\title{
Acute and sub-chronic toxicity of condensate produced from olive mill wastewater using solar energy in mice
}

\author{
Bahaa Al-Trad ${ }^{1}$, Sameh Gharaibeh ${ }^{2}$, Ameerah Qeshawy², Mazhar Salim Al Zoubi ${ }^{3}$, Almuthanna K. \\ Alkaraki*1, Sahar Omari $^{1}$, Malek Shehab ${ }^{1}$ \\ ${ }^{1}$ Department of Biological Sciences, Faculty of Science, Yarmouk University, Irbid 21163, Jordan. \\ ${ }^{2}$ Department of Earth \& Environmental Sciences, Faculty of Science, Yarmouk University, Irbid 21163, Jordan. \\ ${ }^{3}$ Department of Basic Medical Sciences, Faculty of Medicine, Yarmouk University, Irbid 21163, Jordan. \\ * Corresponding author: Almuthanna K. Alkaraki Email: alkaraki@yu.edu.jo
}

Received: June 6, 2020. Revised: November 20, 2020. Accepted: December 5, 2020. Published: January 11, 2021.

\begin{abstract}
Olive mill wastewater (OMW) is one of the environmental challenges associated with the olive oil industry. This study was carried out to investigate the potential acute and sub-chronic toxicity of oral treatment of OMW condensate in mice. Different doses $(250,500,1000$, $2000,4000,8000 \mathrm{mg} / \mathrm{kg}$ ) were applied once to investigate acute toxicity. Sub-chronic toxicity was investigated using thirty mice; two groups with $(500,4000 \mathrm{mg} / \mathrm{kg} / \mathrm{body}$ weight $)$ doses along with one control group. Acute toxicity study results showed that the $\mathrm{LD}_{50}$ was greater than the highest tested dose with no signs of systemic toxicity, mortality, or behavioral changes. In addition, the sub-chronic investigation did not show significant changes in behavior, body weight, and vital organs weight/body weight ratio along with no observed differences in the studied hematological parameters. Condensate dose of $500 \mathrm{mg} / \mathrm{kg}$ did not show significant differences in the levels of blood urea nitrogen (BUN), alanine aminotransferase and aspartate aminotransferase (AST). However, the AST serum level was significantly decreased and the serum level of BUN was increased at the dose of $4000 \mathrm{mg} / \mathrm{kg}$. Results suggest that single and repeated oral doses of olive condensate administered orally are safe in mice.

Keywords - Acute toxicity, Sub-chronic toxicity, Olive mill wastewater, Olive condensate, Wastewater management.
\end{abstract}

\section{INTRODUCTION}

The global consumption of olive oil has increased dramatically due to its nutritional value and its health benefits [1]. This trend led to an increase in the cultivation of olive trees to cover the increased global demand. Globally, more than eleven million hectares of agricultural lands, in about forty-seven countries, are planted with olive trees. The world's majority of olive trees $(98 \%)$ are cultivated and harvested in the Mediterranean region, thus the olive oil extraction industry is growing continuously in almost all Mediterranean countries [2].

Olive oil extraction is associated with various environmental impacts including high levels of water and energy consumption, discharging of olive mill wastewater (OMW) and pomace (solid by-product) in addition to other environmental emissions such as noise and air pollution [2]. One of the challenges of the olive oil industry is the discharge of large volumes of the olive mill wastewater OMW [3]. The composition and organic load of the OMW are governed by the vegetation water of the olives, efficiency of the OMW in separating the oil from the OMW and storage time of the olives before processing. The organic load in the OMW contains phenols, polyphenols, chlorophyll, humic acids, polyalcohol, sugar and much more known and unknown compounds of 
soluble, colloidal and suspended forms [4]. In general, OMW is acidic ( $\mathrm{pH} 4.6-5.3)$ with high organic load (50 - >150 g/l) and intensive odor. OMW acidity is related to their continents of phenolic compounds and humic acids, while the phytotoxicity is related to the high concentration of phenols [5] and dissolved solids in the OMW (Condensate). The condensate is free of suspended solids, transparent, colorless and more acidic than OMW, it contains high concentrations of dissolved volatile organic compounds [6-8].

Different Strategies were proposed for safe disposal of olive condensate and realated pollutants [7, 9], however, biological effects of condensate on laboratory animals have not been investigated adequately.

Olive trees cultivation and olive oil production are one of the most important economic and agricultural activities in Jordan. Moreover, olive oil is considered as an important part of Jordanian culture being used in folk medicine recipes and as a main component of traditional Jordanian dishes. There are about 17 million olive trees in Jordan and more than $95 \%$ of the Jordanian olive production is used for the production of olive oil. Recently, more than 110 three-phase olive mills were reported in Jordan with more than 140 production lines [3]. The yearly discharge of OMW was reported to be more than 400 $000 \mathrm{~m}^{3}$ via lagooning and the trend is increasing in Jordan [3]. Lagooning, anaerobic digestion, co-composting with pomace, irrigation, bentonite treatment and other methods were used for OMW treatment/disposal, but without finding the ultimate solution that is technically acceptable, economically feasible and meets all environmental demands.

OMW was recently separated into condensate and biofuel using solar still units [3]. The biofuel was evaluated [3], while the condensate still needs further studies. It is important to investigate the toxicity of olive condensate in laboratory animals. Hence this study aimed to evaluate the potential acute and sub-chronic toxicity of the olive condensate in laboratory mice.

\section{MATERIAL AND METHODS}

\section{A. Condensate preparation and determination of acute toxicity} (LD50)

OMW condensate separation procedure using the solar distillation technique was previously reported earlier in detail $[3,6]$. All animals' procedures were ethically approved by the Yarmouk University Institutional Animal Care and Use Committee, following the guideline of the National Institutes of Health guide for the care and use of laboratory animals. Experiments were carried out on 4 to 7 weeks old females' albino Balb/c mice ( $\mathrm{n}=60$; weighing 24-33 g) supplied by Yarmouk University animal house facility. Mice were maintained in a controlled atmosphere of $12 \mathrm{hrs}$ light-dark cycle, $25 \pm 2 \mathrm{C}^{\circ}$ room temperature with free access to food and water supply. To determine the $\mathrm{LD}_{50}$ of the condensate, mice $(\mathrm{n}=10$ each group) were orally treated with different condensate doses $(250,500,1000,2000,4000,8000 \mathrm{mg} / \mathrm{kg})[10]$. The mortality rate and sign of toxicity were observed regularly for the first $24 \mathrm{hrs}$, and daily for two weeks. Toxicity was evaluated using an early proposed scale of Hodge and Sterner [11].

\section{B. Sub-chronic toxicity study}

Thirty mice were randomly divided into 3 groups: two groups that were treated orally with two different condensate doses $(500,4000 \mathrm{mg} / \mathrm{kg}$ body weight) for 30 days along with a control group (10 animals) treated with distilled water [12]. During the experiment, animals were observed for mortality and any changes in general behavioral patterns and physical appearance. By the end of the treatment period, all mice were killed and blood samples were collected for further hematological and biochemical parameters analysis. Then, vital organs (heart, lung, liver, and kidney) were removed and weighed.

\section{Hematological and biochemical analysis}

Different hematological parameters were investigated. Those include white blood cells (WBC), red blood cells (RBC), hemoglobin (HB), hematocrit (HCT), mean corpuscular volume $(\mathrm{MCV})$, mean corpuscular hemoglobin $(\mathrm{MCH})$, and mean corpuscular hemoglobin concentration (MCHC), which were determined using automated hematology analyzer. Serum samples were separated by centrifugation at $3000 \mathrm{rpm}$ for 15 minutes and the obtained serum was stored at $-80{ }^{\circ} \mathrm{C}$ for further analysis. Serum was analyzed for blood urea nitrogen (BUN), alanine aminotransferase (ALT) and aspartate aminotransferase (AST) using an automated biochemistry analyzer.

\section{Statistical analysis}

Results were expressed as the mean \pm Standard Error of mean (SEM). Results were analyzed by one-way analysis of variance (ANOVA) using SPSS software (version 22.0) [13]. The $P$-value was considered to be significant when it is value $<$ 0.05 .

\section{RESULTS}

\section{A. Acute toxicity studies}

The $\mathrm{LD}_{50}$ was greater than the highest tested dose $(8000$ $\mathrm{mg} / \mathrm{kg}$ ). Also, animals did not show any signs of systemic toxicity (such as irritability, ataxia, sedation, seizures, and diarrhea), mortality, changes in body weight or behavioral changes during the next 14-days after the exposure time. This indicates that acute exposure to the condensates can be considered non-toxic and safe.

\section{B. Sub-chronic toxicity studies.}

Sub-chronic oral administration of condensate at different doses $(500,4000 \mathrm{mg} / \mathrm{kg})$ of body weight for 30 days did not produce apparent variation in common behavior of the mice, significant changes in feed and water intake compared to the control group and all animals were survived throughout the study time.

\section{Body weight and organ weight/body weight ratio}

The change in mean body weight and vital organs (heart, lung, liver, spleen, and kidney) weight/body weight ratio at the end of the period of treatment in both control and condensate treated groups are shown in Table 1. Results showed no significant difference $(p>0.05)$ in the body weight between condensate treated and control animals. Similarly, there were 
NTERNATIONAL JOURNAL OF BIOLOGY AND BIOMEDICAL ENGINEERING

DOI: $10.46300 / 91011.2021 .15 .2$

no significant changes $(p>0.05)$ in the organs weight/body weight ratios in the condensate treated groups compared to the control group ( $p>0.05$; Table 1$)$.
Volume 15, 2021

16]. In the present study, sub-chronic oral administration of two different doses of the condensate showed no harmful impact on the relative vital organs weight and on the total body weight,

Table 1. Effect of condensate on vital organs/body weight ratio.

\begin{tabular}{|l|c|c|c|c|c|c|}
\hline \multicolumn{2}{|c|}{} & \multicolumn{5}{c|}{ Organ weight/body weight ratio } \\
\hline & $\begin{array}{c}\text { Body Weight } \\
(\mathbf{g})\end{array}$ & Heart & Lung & Liver & Kidney & Spleen \\
\hline Control & $26.2 \pm 0.58$ & $0.117 \pm 0.01$ & $0.218 \pm 0.01$ & $1.136 \pm 0.05$ & $0.262 \pm 0.01$ & $0.152 \pm 0.01$ \\
\hline $\begin{array}{l}\text { Condensate } \\
(\mathbf{5 0 0 m g / k g )}\end{array}$ & $27.5 \pm 0.80$ & $0.127 \pm 0.01$ & $0.258 \pm 0.01$ & $1.184 \pm 0.07$ & $0.267 \pm 0.01$ & $0.156 \pm 0.01$ \\
\hline $\begin{array}{l}\text { Condensate } \\
(\mathbf{4 0 0 0} \mathbf{m g} / \mathbf{k g})\end{array}$ & $27.1 \pm 0.53$ & $0.127 \pm 0.01$ & $0.213 \pm 0.01$ & $1.194 \pm 0.07$ & $0.251 \pm 0.01$ & $0.133 \pm 0.01$ \\
\hline
\end{tabular}

\section{Hematological and biochemical analysis}

The effect of sub-chronic administration of condensate on selected hematological indices is shown in Table 2. The results showed that there was no significant difference $(p>$ $0.05)$ in all parameters measured between the condensate treated group and control group. In addition, $500 \mathrm{mg} / \mathrm{kg}$ condensate dose did not significantly affect the serum AST, ALT and BUN levels. However, $4000 \mathrm{mg} / \mathrm{kg}$ dose significantly $(p<0.05)$ decrease the AST serum level and increase BUN level $(p<0.05$; Table 2$)$.

\section{DISCUSSION}

A global environmental concern in the olive mill industry is the disposal of large quantities of byproducts. OMW is a serious problem in public health with a negative impact on soil and water quality. OMW contains different compounds with biological activity [14]. Previous study provided interesting information on a novel technique that can be used to solve this problem in a safe way and low economic cost via OMW processing into condensate and biofuel using solar still units [6] . However, acute and sub-chronic toxicity of the condensate in laboratory animals were not assessed. The main aim of this study, therefore, was to investigate acute and sub-chorionic toxicity of olive condensate and the effect of condensate on hematological, biochemical and histological parameters and tissue structures in mice.

During the acute study, animals did not show any signs of acute systemic toxicity or mortality and the $\mathrm{LD}_{50}$ was greater than the highest tested dose $(8000 \mathrm{mg} / \mathrm{kg})$. The $\mathrm{LD}_{50}>8,000$ $\mathrm{mg} / \mathrm{kg}$ classified the condensate as practically non-toxic according to the Hodge and Sterner scale [11]. Therefore, condensates can be considered non-toxic.

Body weight changes and vital organs weight are considered among important indices of pathological and physiological status in laboratory animals. Heart, liver, kidney, spleen and lungs are the vital organs that could be affected by different metabolic reactions caused by drugs and chemicals toxicity $[15$,

\begin{tabular}{|c|c|c|c|}
\hline Parameter & Control & $\begin{array}{l}\text { Condensate } \\
(500 \mathrm{mg} / \mathrm{kg})\end{array}$ & $\begin{array}{l}\text { Condensate } \\
(4000 \mathrm{mg} / \mathrm{kg})\end{array}$ \\
\hline $\mathrm{WBC}\left(\times 10^{\wedge} 3 / \mu \mathrm{l}\right)$ & $10.65 \pm 1.39$ & $11.3 \pm 2.24$ & $8.075 \pm 1.05$ \\
\hline $\operatorname{RBC}\left(\times 10^{\wedge} 6 / \mu \mathrm{l}\right)$ & $9.57 \pm 0.272$ & $11.2 \pm 0.333$ & $9.72 \pm 0.56$ \\
\hline HB (g/dl) & $13.5 \pm 0.191$ & $15.866 \pm 0.332$ & $13.875 \pm 0.925$ \\
\hline HCT (\%) & $40.3 \pm 0.497$ & $50.133 \pm 1.275$ & $42.75 \pm 2.604$ \\
\hline MCV (fl) & $42.175 \pm 1.23$ & $44.433 \pm 0.635$ & $44.075 \pm 1.844$ \\
\hline MCH (pg) & $14.125 \pm 0.45$ & $14.066 \pm 0.152$ & $14.275 \pm 0.417$ \\
\hline MCHC (g/dl) & $33.475 \pm 0.11$ & $31.666 \pm 0.629$ & $32.45 \pm 0.861$ \\
\hline $\operatorname{AST}(\mathbf{U} / \mathbf{L})$ & $70.8 \pm 9.7$ & $62.6 \pm 5.2$ & $53.4 \pm 4.6^{*}$ \\
\hline ALT(U/L) & $47.6 \pm 7.3$ & $54.3 \pm 4.6$ & $44 \pm 6.9$ \\
\hline BUN(g/dL) & $31.3 \pm 6.0$ & $34 \pm 2.3$ & $53.6 \pm 7.6^{*}$ \\
\hline
\end{tabular}

concluding that the condensate is non-toxic on these vital organs.

Liver is the main site of metabolism reactions and elimination of foreign compounds. Due to its unique metabolic functions and its relationship with the gastrointestinal tract, liver is an important target of drugs and xenobiotic (chemicals that are not normally produced or expected to be present in the body) detoxification processes [17]. Metabolic alteration of 
DOI: $10.46300 / 91011.2021 .15 .2$

chemical compounds into reactive intermediate species, such as free radicals, prompted liver injuries via the initiation of free radicals, leading to oxidative stress. The disturbing oxidative stress causes deregulation of cell signaling pathways, dysfunction of biomolecules, and could lead to cell death [17]. The tested blood levels of the aminotransferases ALT and AST are often used as marker enzymes to indicate liver damage [1820]. Both ALT and AST catalyze the transfer of an amino group from an amino acid to $\alpha$-ketoglutarate [20]. ALT localized in the liver mainly is released into the bloodstream as the result of liver injury, thus is a more specific marker of hepatocellular cell injury than AST. On the other hand, AST is widely distributed in other organs in addition to the liver including cardiac muscle, skeletal muscle, kidney and brain tissue and it is released into the serum when any one of these tissues is damaged [21]. Severe ( $>20$ times, $1000 \mathrm{U} / \mathrm{L}$ ) or moderate (3-20 times) elevations of serum aminotransferases levels are observed most often in cases with diseases that affect hepatocytes such as hepatitis and toxin-induced liver necrosis $[18,19]$. The results of the present study suggest that the condensate did not cause any hepatocellular injury as the values of serum ALT and AST enzymes were almost similar in all the groups and no significant difference was observed between the groups. This was supported by the absence of histopathological changes in the liver of treated mice (data not shown).

Kidneys play a major role in eliminating waste metabolites and xenobiotics from circulation. Since xenobiotic excretion occurs mainly in proximal tubules and during this process, the kidney may become susceptible to nephrotoxicity [22]. BUN is a nitrogen-containing compound produced by the liver as the end product of protein metabolism and the urea cycle. When renal clearance decreases in acute and chronic renal failure, serum urea is increased [23]. In the current study, BUN levels as an indicator of kidney function showed no significant differences between the experimental and control groups at a low dose $(500 \mathrm{mg} / \mathrm{kg})$. However, $4000 \mathrm{mg} / \mathrm{kg}$ dose significantly increased BUN, which indicates that the subchronic administration of high condensate dose may impair renal function. However, the histological analysis confirmed that the condensate at both doses $(500$ and $4000 \mathrm{mg} / \mathrm{kg}$ ) has no negative effect on normal kidney histology (data not shown).

Hematological parameters, such as hematocrit, hemoglobin, and numbers of RBCs and WBCS, can be used as indicators of toxicity. RBCs are exposed to high xenobiotic concentration, and are limited in their ability to respond to injury since they are anucleate cells. Therefore, decreased RBC mass and $\mathrm{RBC}$ indices (MCV, $\mathrm{MCH}$ and $\mathrm{MHCH}$ ) are a common finding in toxicity studies [24]. Decreased RBC production during a toxicity study is associated with changes in RBC indices, decreased reticulocytes, and decreased erythropoiesis. In the present study and after 30 days of treatment with the condensate there was no significant change in the hematological parameters between the control and treatment groups, excluding the occurrence of anemia.

\section{CONCLUSIONS}

The results of the present study suggest that single and repeated oral dosing with the condensate that separated from
Volume 15, 2021

the OMW using the solar system is safe in mice. Renal impairment may result from the administration of a high condensate dose. Further studies are needed in order to determine the chronic toxicity effect of olive condensate. Higher doses should be also applied to assess the acute and sub chronic toxicity of the olive condensate. In addition, the genotoxicity effect of the of the olive oil condensate should be tested.

\section{ACKNOWLEDGMENT}

This work could not be completed without the financial fund from the Deanship of Research and Graduate Studies/Yarmouk University (Irbid, Jordan).

\section{CONFLICT OF INTEREST}

The authors declare no conflict of interest.

\section{REFERENCES}

[1] Dermeche, S., et al., "Olive mill wastes: biochemical characterizations and valorization strategies". Process Biochemistry, 2013. 48(10): p. 1532-1552.

[2] Tsagaraki, E., H.N. Lazarides, and K.B. Petrotos, Olive mill wastewater treatment, in Utilization of By-products and Treatment of Waste in the Food Industry. 2007, Springer. p. 133-157.

[3] Gharaibeh, S. and A.Q. Jaradat, Obtaining a new source of biofuel from olive mill wastewater using solar energy. Energy, Ecology and Environment, 2017. 2(1): p. 29-3.4

[4] Yesilada, Ö., K. Fiskin, and E. Yesilada, The use of white rot fungus Funalia trogii (Malatya) for the decolourization and phenol removal from olive mill wastewater. Environmental technology, 1995. 16(1): p. 95-100.

[5] Gonzalez, M., et al., Studies on antibacterial activity of waste waters from olive oil mills (alpechin): inhibitory activity of phenolic and fatty acids. Chemosphere, 1990. 20(3-4): p. 423432.

[6] Jaradat, A.Q., S. Gharaibeh, and M. Abu Irjei, The application of solar distillation technique as a mean for olive mill wastewater management. Water and Environment Journal, 2018. 32(1): p. 134-140.

[7] Papaioannou, E.H., et al., Characterization of condensates from an indirect olive oil pomace drying process: The effect of drying temperature . Journal of Environmental Chemical Engineering, 2013. 1(4): p. 831-837.

[8] Karabelas, A., Characterization of condensates from an indirect olive oil pomace drying process: 
NTERNATIONAL JOURNAL OF BIOLOGY AND BIOMEDICAL ENGINEERING DOI: $10.46300 / 91011.2021 .15 .2$

Volume 15, 2021

The effect of drying temperature. Journal of environmental chemical engineering, 2 .013 http://dx.doi.org/10.1016/j.jece.2013.07.025.

[9] Masi, F., et al., Evaporation-condensation of olive mill wastewater: Evaluation of condensate treatability through SBR and constructed Wetlands. Ecological Engineering, 2014.

[10] Oecd, Oecd Guidelines for the Testing of Chemicals: Acute Oral Toxicity-Acute Toxic Class Method (423). 2001.

[11] Hodge, A. and B. Sterner, Toxicity classes. Canadian Center for Occupational Health and Safety. Retrieved from http://www. ccohs. ca/oshanswers/chemicals/id50. htm, 2005.

[12] OECD, Guidelines for The Testing of Chemicals: Repeated Dose 28-Day Oral Toxicity Study in Rodents, OECD/OCDE 407. . 2008.

[13] IBM, IBM SPSS Statistics for Windows. Version 22.0. Armonk, NY: IBM Corp., Released 2013.

[14] Rusan, M.J., A.A. Albalasmeh, and H.I. Malkawi, Treated olive mill wastewater effects on soil properties and plant growth. Water, Air, \& Soil Pollution, 2016. 227(5): p. 135.

[15] Dybing, E., et al., Hazard characterisation of chemicals in food and diet: dose response, mechanisms and extrapolation issues. Food and Chemical Toxicology, 2002.40 (2-3): p. 237-282.

[16] Jothy, S., et al., Acute oral toxicity of methanolic seed extract of Cassia fistula in mice. Molecules, 2011. 16(6): p. 5268-5282.

[17] Gu, X. and J.E. Manautou, Molecular mechanisms underlying chemical liver injury. Expert reviews in molecular medicine, 2012. 14.

[18] Diana Nicoll, C., Appendix: Therapeutic drug monitoring and laboratory reference ranges. Current medical diagnosis and treatment. Stephen JM, Maxine AP. 46th edition, Mc Graw hill, 2007: p. 1767-1775.

[19] Gowda, S., et al., A review on laboratory liver function tests. The Pan African Medical Journal, 2009. 3.

[20] McGill, M.R., The past and present of serum aminotransferases and the future of liver injury biomarkers. EXCLI journal, 2016. 15: p. 817.

[21] Kwo, P.Y., S.M. Cohen, and J.K. Lim, ACG clinical guideline: evaluation of abnormal liver chemistries. The American journal of gastroenterology, 2017. 112(1): p. 18.

[22]George, B., et al., Xenobiotic transporters and kidney injury. Advanced drug delivery reviews, 2017. 116: p. 73-91.

[23] Gowda, S., et al., Markers of renal function tests. North American journal of medical sciences, 2010. 2(4): p. 170.

[24] Everds, N.E., Evaluation of clinical pathology data: correlating changes with other study data. Toxicologic pathology, 2015. 43(1): p. 90-97.

\section{Creative Commons Attribution License 4.0 (Attribution 4.0 International, CC BY 4.0)}

This article is published under the terms of the Creative Commons Attribution License 4.0

https://creativecommons.org/licenses/by/4.0/deed.en_US 